\title{
Density effects on ammonium nitrate toxicity on amphibians. Survival, growth and cannibalism
}

\author{
Manuel E. Ortiz-Santaliestra ${ }^{\mathrm{a}, *}$, María José Fernández-Benéitez ${ }^{\mathrm{a}}$, Adolfo Marco ${ }^{\mathrm{b}}$

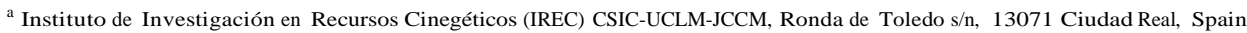 \\ ${ }^{\mathrm{b}}$ Estación Biológica de Doñana (CSIC), C/Américo Vespucio s/n, 41092 Sevilla, Spain
}

Keywords:

Cannibalism

Fertilizer

Intraspecific competition

Natural stressor

Salamander a b s t r a c t

Temporary ponds where many amphibians breed experience a gradual desiccation that leads to growing larval densities, which can reduce tadpole survival rates and increase cannibalistic interactions among carnivorous salamander larvae. Concentrations of many agrochemicals, including nitrogenous fertilizers, can also increase as the water volume decreases. We analyzed the effects of ammonium nitrate fertilizer at two larval densities on growth and survival of Rana dalmatina tadpoles, and on cannibalistic behaviors of Salamandra salamandra larvae. We observed synergistic lethal effects until day 17 of exposure, when ammonium nitrate-related mortality of tadpoles was five times greater at high than at low density. The fertilizer impaired tadpole growth. This effect was stronger at low density than at high density. In the absence of ammonium nitrate, the incidence of cannibalism was higher at high than at low larval density. However, fertilizer exposure removed this density-dependent effect, which, under field conditions, would negate some potentially advantageous effects of cannibalism such as reduced intraspecific competition and the stimulation of defensive behaviors.

\section{Introduction}

Amphibians are not usually only exposed to a single pollutant in their natural habitats but to various substances whose combination can have additive, synergistic, or antagonist effects (Altenburger et al., 2003). Even when a single pollutant exists in the environment there are natural stressors that can indirectly influence the final response of amphibians to contaminants. Knowing how these natural stressors interact with the effects of pollutants is essential in understanding the impacts of contaminants on amphibian populations in their natural environments (Relyea and Hoverman, 2006).

One of the ecological variables affecting amphibians in the aquatic environment is the density of individuals, which can reduce per capita resources, thereby increasing the intensity of intraspecific competition (Wilbur, 1980). Semlitsch and Walls (1993) showed that increased larval density reduced growth rates in two species of salamanders of the genus Ambystoma. Similarly, Scott and Fore (1995) showed that food availability affected growth, body condition, and metabolism in Ambystoma opacum. In general,

\footnotetext{
* Corresponding author. Tel.: +34 926295450; fax: +34926295451. E-mail addresses: manuele.ortiz@uclm.es (M.E. Ortiz-Santaliestra), mariajose.fbeneitez@uclm.es (M.J. Fernández-Benéitez), amarco@ebd.csic.es (A. Marco).
}

high individual densities increase physiological and environmental stress (Sibly, 1999), which manifests in reduced growth rate and size at metamorphosis, as well as in prolonged larval periods in both anurans (Semlitsch and Caldwell, 1982; Skelly, 1995) and urodeles (Scott, 1990; Van Buskirk and Smith, 1991). This stress can sometimes become lethal to larvae (Semlitsch and Caldwell, 1982; Loman, 2004). Furthermore, larvae that develop in environments with high individual densities may suffer from reduced growth rates later on during their juvenile life (Altwegg, 2003), although such reduction in growth can be compensated during late larval and juvenile stages (Boone, 2005; Distel and Boone, 2009). These findings demonstrate that larval density plays a crucial role in regulating the dynamics of amphibian populations in both the medium and long term (e.g. Van Buskirk and Smith, 1991).

The combined effects of increased densities and pollution on larval amphibians can be understood from different perspectives; if the effects are considered only at the organism level, elevated density acts as a stressor, producing detrimental effects that add to, or multiply those of the pollutant (see results of Richter et al., 2009 with Lithobates catesbeianus). On the other hand, if the study organisms are considered as part of an ecosystem, with ecological interactions then being taken into account, pollutants can sometimes mitigate the adverse effects of elevated density (or elevated competition) by increasing food resources under certain circumstances. For example, insecticides that remove zooplankton from the ponds promote an increase in phytoplankton (Hanazato and 

Yasuno, 1990; Fairchild et al., 1992), reducing the competition among filtering tadpoles (Relyea, 2005). Nevertheless, other chemicals, or the same chemicals in terms of their effects on other species, may have the opposite effect on food resources. In the short term, insecticides can also promote peryphyton development, which would favor growth of rasping tadpoles (Boone et al., 2005). However, by indirectly promoting phytoplankton growth, insecticides can cause a reduction in periphyton in the long term, therefore limiting the food resources for rasping tadpoles, and enhancing the negative effects of high densities (Relyea and Diecks, 2008).

The effects of high larval densities are not exclusively linked to increased competition for nutrients. Elevated larval density is also associated with the occurrence of cannibalism among larvae of some species, particularly salamanders (Collins and Cheek, 1983; Crump, 1983). Cannibalism has several benefits; by consuming their conspecifics, cannibal larvae eliminate intraspecific competition (Polis, 1981; Crump, 1983) and grow at a faster rate than non-cannibal forms (Crump, 1990; Wildy et al., 1998). Moreover, recurrent cannibalism within a population can stimulate the development of antipredatory behaviors among its individuals, thus increasing survival probabilities when facing predators (Chivers et al., 1997; Wildy et al., 1999), although this direct benefit can be limited by the high energetic expenditure associated with such phenotypic plasticity (DeWitt et al., 1998). Cannibals have a greater chance of survival than their non-cannibal conspecifics (Polis, 1981). In fact, in some amphibian species with several cohorts within the same breeding season, cannibalism could be part of the evolutionary strategy, as individuals from later cohorts can be consumed by their older, larger conspecifics (Chen et al., 2001; Eitam et al., 2005). Whereas a number of ecosystem-focused studies have analyzed the effects of water pollution on competitive interactions among amphibian larvae, no information exists about the impact of pollutants on cannibalistic interactions.

The aim of this work was to investigate the combined effects of a commonly used fertilizer, ammonium nitrate, on larval amphibians at different densities. We assessed the two factors in combination, considering them as stressors, on the agile frog (Rana dalmatina) tadpoles. In Northern Spain, this species usually breeds in ponds and lakes located in oak tree forests with abundant submerged vegetation, surrounded by crop fields or grazing areas (Gosá, 1994) and, thus, potentially exposed to water eutrophication. In addition, we studied how the exposure to the fertilizer affected the incidence of cannibalistic interactions among common salamander (Salamandra salamandra) larvae raised at different densities. Cannibalism in S. salamandra, a species with ovoviviparous or viviparous reproduction, is a well-known phenomenon thought to be part of the normal process of biphasic reproduction in some populations (Buckley et al., 2007). However, nothing is known about how chemical compounds in the environment may affect these interactions among conspecifics.

Ammonium nitrate is one of the most commonly used fertilizers worldwide. Its application on crop fields has grown as part of the global increase of the use of inorganic nitrogenous fertilizers. Excess ammonium nitrate flows via runoff into nearby water bodies, where nitrogen concentrations may reach levels that are harmful for aquatic wildlife (Vitousek et al., 1997). Moreover, gradual desiccation of temporary ponds that happens during late spring and summer usually causes an increase in nitrate and ammonium concentrations (Fernández-Aláez and FernándezAláez, 2010). Ammonium nitrate produces deleterious effects on amphibian larvae, including increased mortality, anatomical abnormalities, and delayed growth and development (Ortiz et al., 2004). Several studies have also pointed to the negative effects of ammonium nitrate when combined with natural stressors such as predators (Burgett et al., 2007; Griffis-Kyle and Ritchie, 2007; Ortiz-Santaliestra et al., 2011) or increased water salinity
(Ortiz-Santaliestra et al., 2010a). Furthermore, exposure to the chemical affects larval activity and behavior (Xu and Oldham, 1997; Ortiz-Santaliestra et al., 2010b). However, to the best of our knowledge, no work has yet analyzed how the toxicity of this fertilizer varies as a function of individual density.

\section{Materials and methods}

\subsection{R. dalmatina experiment}

In February 2004, we collected fragments of five different R. dalmatina clutches from the Orgi Natural Area (Navarra, N Spain). We transported eggs to the laboratory, where they developed at an ambient temperature of $20{ }^{\circ} \mathrm{C}$ under a natural sunlight photoperiod. The experiment started when tadpoles were able to swim freely, at developmental stage 25 according to Gosner (1960). We used aquaria with a square floor of $160 \times 160 \mathrm{~mm}$. We added $3 \mathrm{~L}$ of water filtered with activated carbon to remove chlorine, nitrate, and ammonia. The height of the water column was $117.2 \mathrm{~mm}$. We introduced a cylindrical cage into each aquarium that had a $58 \mathrm{~mm}$ diameter and that was $180 \mathrm{~mm}$ high, so that the top part of the cage remained above the water surface. The effective water volume was $310 \mathrm{~mL}$ inside the cage and $2690 \mathrm{~mL}$ outside the cage. We randomly assigned each aquarium to a density level - either low (individuals outside the cage) or high (individuals inside the cage) - and to a nominal ammonium nitrate concentration ( 0 , 22.6, 90.3, and $180.6 \mathrm{mg} \mathrm{N}-\mathrm{NO}_{3} \mathrm{NH}_{4} / \mathrm{L}$ ) obtained from ammonium nitrate salt that was $99 \%$ pure (Merck, Darmstaad, Germany). No aquarium had individuals inside and outside the cage. Considering the pond dimensions, breeding female population and average fecundity in the site where we collected the eggs (as described in Sarasola, 2010), the maximum density in conditions of maximum water level would be around 0.2 tadpoles/L (i.e. $>10$ times lower than the lowest experimental density). While the experimental densities used in the present study could then be interpreted as too high, we must consider that spawning site selection is usually dependent on the microhabitat (Ficetola et al., 2006), and thus eggs and young tadpoles concentrate in specific zones of the ponds. Consequently, tadpole densities could potentially reach, and even surpass, the lowest experimental density used in the present study. We selected the lowest experimental ammonium nitrate concentration from the maximum level of nitrate in drinking water (European Council, 1998). The intermediate concentration has sometimes been detected in ponds from agricultural areas in Spain where amphibians breed (Ortiz-Santaliestra et al., 2010a). Finally, we used the highest concentration as a positive control in order to ensure a detectable effect to determine the influence of density on ammonium nitrate toxicity. Each combination of density $\times$ ammonium nitrate levels was replicated three times in a block design. The number of replicates was selected from the available number of collected specimens, which was determined by collection permits.

The experiment followed a static-renewal design, with complete water renewal every five days. Before each water change, we measured $\mathrm{pH}$ (pH-meter Hanna ${ }^{\circledR} \mathrm{HI}$ 8314; Hanna Instruments, Eibar, Spain) and dissolved oxygen (oximeter Handylab ${ }^{\circledR}$ $\mathrm{OXI} /$ Set; Schott-Geräte, Hofheim, Germany) in all aquaria, as well as the concentrations of ammoniacal and nitric nitrogen via colorimetric methods using kits Visocolor ${ }^{\circledR}$ ECO 931008 and 931 041 (Macherey-Nagel, Düren, Germany). We compared chemical parameters among treatments using repeated measures analyses of the variance (ANOVA). We readjusted ammonium nitrate nominal concentrations after every water change.

We introduced either inside or outside the cage in each aquarium, seven tadpoles that were randomly selected from among those 
of a similar size. For this purpose, from the pull of tadpoles raised in the laboratory we discarded those individuals that were smaller or larger than the average to the human eye. Then, we distributed the remaining tadpoles across the experimental aquaria, after checking initial size variability by measuring total length (snout to tip of the tail) of ten individuals with a digital caliper to the nearest $0.01 \mathrm{~mm}$. Mean initial length $( \pm 1 \mathrm{SE})$ was $17.48 \pm 0.14 \mathrm{~mm}$.

The experiment lasted for 25 days. We fed tadpoles ad libitum with boiled lettuce. We checked all the aquaria daily and annotated and removed the dead animals. We used the aquarium (replicate) as the experimental unit, and calculated cumulative mortality rates as the number of dead tadpoles since the beginning of the experiment with respect to the initial number of tadpoles in each aquarium. At the end of the experiment, we measured all survivors (snout to tip of the tail) with a digital caliper to the nearest $0.01 \mathrm{~mm}$.

\subsection{S. salamandra experiment}

In December 2004, we collected 144 S. salamandra larvae with a mean total length of $20.03( \pm 2.84) \mathrm{mm}$ from Vilvestre (Salamanca, $\mathrm{W}$ Spain). We followed the same experimental design as in the R. dalmatina experiment, altering the number of individuals per aquarium (eight instead of seven) and not using the highest ammonium nitrate concentration that was used in the previous experiment (180.6 mg N-NO $\mathrm{NH}_{4} / \mathrm{L}$ ). Unlike the previous assay, the experimental densities used for $\mathrm{S}$. salamandra seem above those expected in natural conditions (Eitam et al., 2005). However, in the area from which the study animals were collected, S. salamandra breeds in temporary ponds that suffer a desiccation process as the larval development progresses (Alarcos et al., 2003). Hence, cannibalism might become very frequent in the field during the later larval stages as a consequence of the increased density. We fed larvae ad libitum with frozen chironomid larvae (MBF Bvba, Essen, Belgium).

We checked aquaria at least four times per day, with a maximum interval between consecutive checks of eight hours. We took note of dead individuals, as well as of cases of cannibalism when we observed a larva eating another one or a larva showing symptoms of having been bitten by a conspecific. Additionally, we also considered as cannibalized animals those that we found healthy at a given sampling and that had disappeared at the next one, even though we did not directly observe those animals to have been consumed by their conspecifics. We calculated cumulative mortality rates with and without considering the individuals that were cannibalized. We calculated cannibalism rates as the number of eaten larvae at each given time divided by the initial number of larvae. At the end of the experiment, we measured all survivors (snout to tip of the tail) with a digital caliper to the nearest $0.01 \mathrm{~mm}$.

\subsection{Statistical analyses}

We used the aquarium as experimental unit, and all the variables were calculated as average values among aquaria. In order to meet the assumptions of parametric statistics, mortality and cannibalism rates were arcsine of the square root transformed, and larval sizes were log transformed. We confirmed the normality of the variables with a Shapiro-Wilk's test. We analyzed the combined effects of ammonium nitrate and density on daily mortality rates over time with two-way repeated measures ANOVAs, with the daily increase in cumulative mortality as the dependent variable. We checked the times at which these lethal effects occurred with two-way ANOVAs for each day of exposure. We also analyzed the combined effects of both stressors on larval size and cannibalism rate with two-way ANOVAs. When we detected a significant effect of the fertilizer, we ran Tukey post hoc tests to determine the specific concentration that was causing such an effect. We conducted Bonferroni adjustments for multiple-test comparisons to minimize the risks of type I errors. We considered probability values below 0.05 as significant and values below 0.1 as marginally significant. This threshold for marginal significance was consider only to decide whether further exploration needed to be conducted with data or not, and we rejected the null hypothesis only when any of these subsequent analyses showed a p-value below 0.05 . We carried out this procedure to minimize the risk of committing type II errors, which are common in wildlife studies with sample size limited by bioethical reasons. We analyzed statistical power with the software G*Power 3.1.2 (Universität Kiel, Germany). We conducted the rest of statistical analyses with the software IBM SPSS Statistics 19 (IBM Corporation, Armonk, NY, USA).

\section{Results}

\subsection{R. dalmatina experiment}

Statistical power of all analyses was above 0.90. All controls at low density survived while those raised at high density showed a mortality rate of $14 \%$. Both ammonium nitrate exposure and high individual density significantly reduced survival probabilities of tadpoles (Table 1). At the highest fertilizer concentration (180.6 mg $\mathrm{N}-\mathrm{NO}_{3} \mathrm{NH}_{4} / \mathrm{L}$ ), we detected lethal ammonium nitrate effects at day 7 of exposure, with an average ( $\pm 1 \mathrm{SE})$ mortality rate of $50.0( \pm 11.5) \%$. At the intermediate concentration $(90.3 \mathrm{mg}$ $\mathrm{N}-\mathrm{NO}_{3} \mathrm{NH}_{4} / \mathrm{L}$ ), we observed lethal effects at day 12 , with an overall mortality of $45.2( \pm 18.6) \%$ in individuals exposed to this level. Finally, the mortality recorded at the lowest concentration did not differ statistically from that of the controls. Individuals raised at high density exhibited reduced survival probabilities after 7 days

Table 1

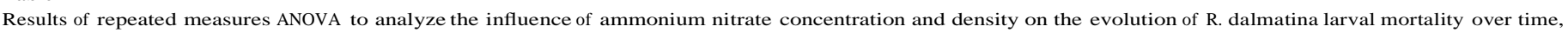

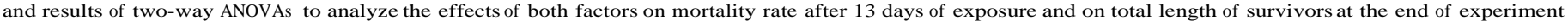
(25 days).

\begin{tabular}{|c|c|c|c|c|c|}
\hline Variable & Source of variation & Mean square & $\mathrm{df}$ & $\mathrm{F}$ & $\mathrm{p}$ \\
\hline \multirow[t]{5}{*}{ Overall mortality } & Time & 3.62798 & 1 & 42.808 & 0.00001 \\
\hline & Time $\times \mathrm{NO}_{3} \mathrm{NH}_{4}$ & 1.25834 & 3 & 14.848 & 0.00007 \\
\hline & Time $\times$ density & 0.66351 & 1 & 7.829 & 0.01289 \\
\hline & Time $\times \mathrm{NO}_{3} \mathrm{NH}_{4} \times$ density & 0.227423 & 3 & 2.683 & 0.08164 \\
\hline & Error & 0.08475 & 16 & & \\
\hline \multirow[t]{4}{*}{ Mortality (day 13) } & $\mathrm{NO}_{3} \mathrm{NH}_{4}$ & 0.92588 & 3 & 10.176 & 0.00054 \\
\hline & Density & 0.82117 & 1 & 9.025 & 0.00841 \\
\hline & $\mathrm{NO}_{3} \mathrm{NH}_{4} \times$ density & 0.31481 & 3 & 3.460 & 0.04142 \\
\hline & Error & 0.09099 & 16 & & \\
\hline \multirow[t]{4}{*}{ Length } & $\mathrm{NO}_{3} \mathrm{NH}_{4}$ & 0.06142 & 3 & 121.164 & $<0.00001$ \\
\hline & Density & 0.00009 & 1 & 0.183 & 0.67671 \\
\hline & $\mathrm{NO}_{3} \mathrm{NH}_{4} \times$ density & 0.00677 & 3 & 13.349 & 0.00055 \\
\hline & Error & 0.00051 & 11 & & \\
\hline
\end{tabular}




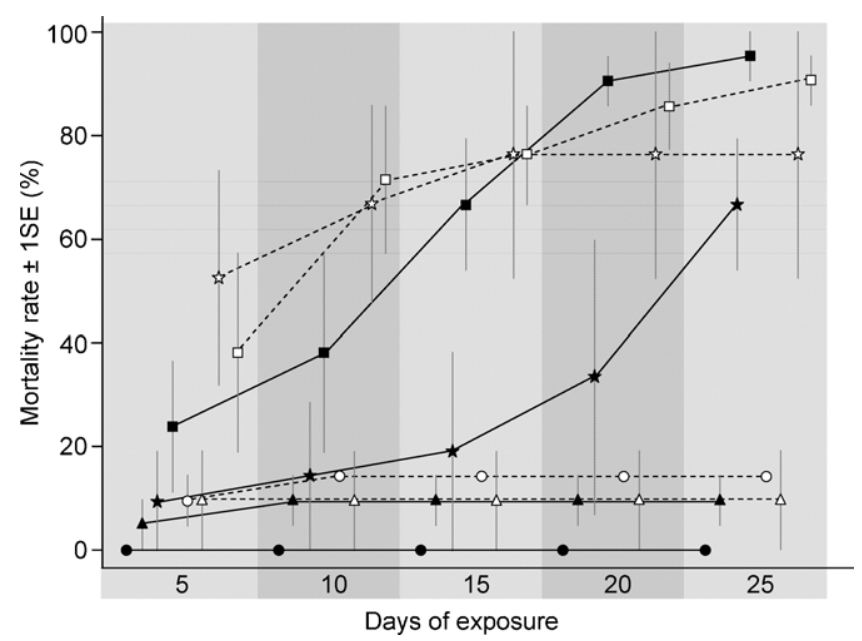

Fig. 1. Mortality rates $( \pm \mathrm{SE})$ per treatment of Rana dalmatina larvae exposed to ammonium nitrate at different densities during 25 days. Circles correspond to controls, triangles to individuals exposed to $22.6 \mathrm{mg} \mathrm{N}-\mathrm{NO}_{3} \mathrm{NH}_{4} / \mathrm{L}$, stars to individuals exposed to $90.3 \mathrm{mg} \mathrm{N}-\mathrm{NO}_{3} \mathrm{NH}_{4} / \mathrm{L}$ and squares to individuals exposed to $180.6 \mathrm{mg} \mathrm{N}-\mathrm{NO}_{3} \mathrm{NH}_{4} / \mathrm{L}$. Continuous lines with black symbols correspond to low density treatments whereas dashed lines with open symbols correspond to high density treatments.

of exposure, with a mortality rate of $38.1( \pm 11.0) \%$ in contrast to the $14.3( \pm 6.1) \%$ in tadpoles that grew at low density.

Because the evolution of the interaction between the two factors over time was marginally significant (Table 1), we conducted daily analyses to test the effect of such interaction at each given exposure time. At certain exposure times, the combination of high individual density with increased ammonium nitrate concentration could result in fatality for tadpoles (Table 1). Specifically, after 13 days of exposure, the mortality rate of individuals exposed to $90.3 \mathrm{mg} \mathrm{N}-\mathrm{NO}_{3} \mathrm{NH}_{4} / \mathrm{L}$ was 5.3 times higher among those that grew at high density than in those growing at low density. In individuals exposed to $180.6 \mathrm{mg} \mathrm{N}-\mathrm{NO}_{3} \mathrm{NH}_{4} / \mathrm{L}$, the mortality rate at high density was twice as high as it was at low density after only three days of exposure; however, Bonferroni corrections revealed that, in this case, differences were not statistically significant. Towards the end of the experiment ( $>17$ days of exposure), although survival was still lower among tadpoles that grew at high density than among those growing at low density, high mortality rates associated with ammonium nitrate exposure reduced the options to detect significant density-related effects (Fig. 1).

The two higher ammonium nitrate concentrations affected tadpole growth rate (Table 1$)$. Average $( \pm 1 \mathrm{SE})$ lengths per

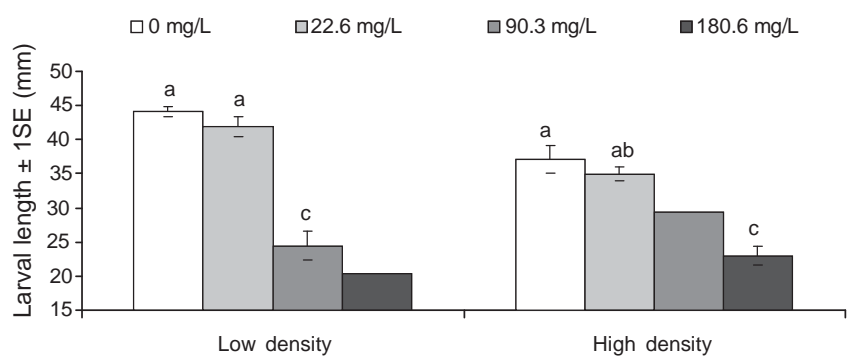

Fig. 2. Larval length $( \pm \mathrm{SE})$ per treatment of Rana dalmatina individuals surviving at the end of the experiment. Lower case letters indicate homogeneous subgroups significantly different from each other $(\mathrm{p}<0.05)$ as defined by Tukey post hoc tests. Some treatments have no error bars or assigned subgroups because only one of the three replicates had survivors at the end of the experiment.

treatment were $40.65( \pm 1.65) \mathrm{mm}$ in controls, $38.42( \pm 1.60) \mathrm{mm}$ in individuals exposed to $45.2 \mathrm{mg} \mathrm{N}-\mathrm{NO}_{3} \mathrm{NH}_{4} / \mathrm{L}, 25.71( \pm 1.51) \mathrm{mm}$

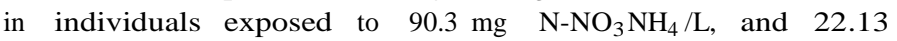
$( \pm 1.04) \mathrm{mm}$ in individuals exposed to $180.6 \mathrm{mg} \mathrm{N}-\mathrm{NO}_{3} \mathrm{NH}_{4} / \mathrm{L}$. In spite of tadpoles at low density showing an average length that was slightly higher than that of tadpoles at high density $(35.18 \pm 3.25$ vs. $32.43 \pm 1.99 \mathrm{~mm}$ ), we did not detect statistical differences for this factor. The interaction between density and fertilizer concentration did affect tadpole length; the ammonium nitrate-related differences in this variable were wider among individuals raised at low density than among those that grew at high density (Fig. 2).

\subsection{S. salamandra experiment}

Statistical power of all analyses was above 0.75 . Mortality by causes other than predation was less than $7 \%$ in all treatments. Consequently, we did not detect lethal effects for any stressor (Table 2). We recorded 35 cases of cannibalism during the experiment, 29 of which were observed directly, and only six were estimated. The probability for these estimated cases being dead before being eaten was very low because: (i) larval mortality not directly associated with predation was decidedly low, and (ii) the few larvae that died by causes other than predation showed visible abnormalities (i.e. abdominal and facial edemas, irregular swimming) during the samplings before they were found dead. We did not observe such symptoms in the supposedly cannibalized larvae.

As expected, larval crowding stimulated the occurrence of cannibalism (mean cannibalism rates $\pm 1 \mathrm{SE}$ : high density: $30.6 \pm 5.2 \%$; low density: $18.1 \pm 3.0 \%$ ), whereas neither ammonium nitrate concentration nor its interaction with individual density affected the cannibalism rate significantly (Table 2). Nevertheless, given that

Table 2

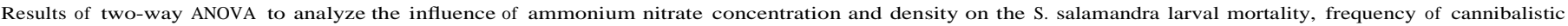
interactions and length of survivors at the end of the experiment.

\begin{tabular}{|c|c|c|c|c|c|}
\hline Variable & Source of variation & Mean square & df & $\mathrm{F}$ & $\mathrm{p}$ \\
\hline \multirow{4}{*}{$\begin{array}{l}\text { Mortality (without } \\
\text { cannibalism) }\end{array}$} & $\mathrm{NO}_{3} \mathrm{NH}_{4}$ & 0.15166 & 2 & 0.731 & 0.50174 \\
\hline & Density & 0.05054 & 1 & 0.245 & 0.62942 \\
\hline & $\mathrm{NO}_{3} \mathrm{NH}_{4} \times$ density & 0.22839 & 2 & 1.108 & 0.36176 \\
\hline & Error & 0.20613 & 12 & & \\
\hline \multirow{4}{*}{$\begin{array}{l}\text { Mortality (with } \\
\text { cannibalism) }\end{array}$} & $\mathrm{NO}_{3} \mathrm{NH}_{4}$ & 0.19102 & 2 & 1.651 & 0.23264 \\
\hline & Density & 0.42360 & 1 & 3.661 & 0.07986 \\
\hline & $\mathrm{NO}_{3} \mathrm{NH}_{4} \times$ density & 0.14432 & 2 & 1.247 & 0.32202 \\
\hline & Error & 0.11571 & 12 & & \\
\hline \multirow[t]{4}{*}{ Cannibalism } & $\mathrm{NO}_{3} \mathrm{NH}_{4}$ & 0.04368 & 2 & 3.203 & 0.07678 \\
\hline & Density & 0.09505 & 1 & 6.971 & 0.02157 \\
\hline & $\mathrm{NO}_{3} \mathrm{NH}_{4} \times$ density & 0.04053 & 2 & 2.973 & 0.08941 \\
\hline & Error & 0.01364 & 12 & & \\
\hline \multirow[t]{4}{*}{ Length } & $\mathrm{NO}_{3} \mathrm{NH}_{4}$ & 0.00109 & 2 & 2.516 & 0.12234 \\
\hline & Density & 0.00018 & 1 & 0.420 & 0.52936 \\
\hline & $\mathrm{NO}_{3} \mathrm{NH}_{4} \times$ density & 0.00025 & 2 & 0.585 & 0.57227 \\
\hline & Error & 0.00043 & 12 & & \\
\hline
\end{tabular}




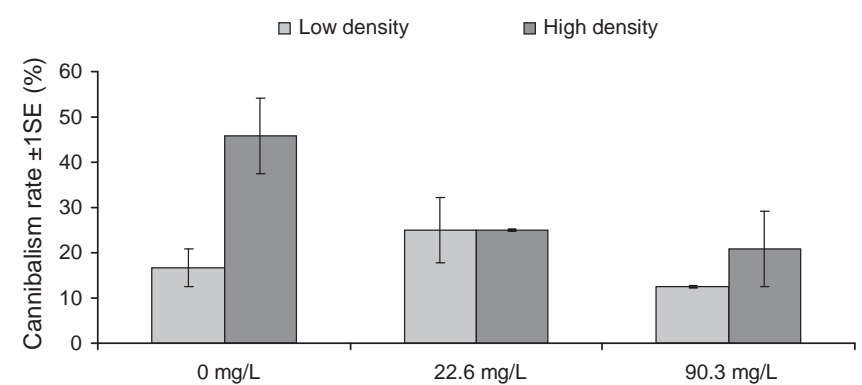

Fig. 3. Cannibalism rate $( \pm S E)$ per treatment among larvae of Salamandra salamandra exposed to ammonium nitrate at different densities.

the $\mathrm{p}$-value of the interaction was marginally significant $(\mathrm{p}<0.1)$, we ran partial analyses for each ammonium nitrate concentration. The occurrence of cannibalism was density-dependent among larvae that were free from the impact of ammonium nitrate; however, when we exposed animals to the fertilizer, density did not influence the number of cannibalized larvae (controls: $F_{1,4}=9.800 ; p=0.035$. Low fertilizer concentration: $F_{1,4}=0.000 ; p=1.000$. High fertilizer concentration: $F_{1,4}=1.000 ; p=0.374$. Fig. 3 ). No treatment affected larval length in this experiment (Table 2).

\subsection{Water chemistry}

Mean $\mathrm{pH}$ and dissolved oxygen were, respectively, 6.62 (range 6.42-6.86) and $5.23 \mathrm{mg} / \mathrm{L}$ (range $4.85-5.83 \mathrm{mg} / \mathrm{L}$ ) in the R. dalmatina experiment, and 6.80 (range 6.52-7.05) and $5.59 \mathrm{mg} / \mathrm{L}$ (range 5.24-5.88 mg/L) in the S. salamandra one. Neither the ammonium nitrate concentration nor the individual density affected $\mathrm{pH}$ or dissolved oxygen in any experiment $(p>0.05)$.

In the R. dalmatina experiment, mean $( \pm \mathrm{SE})$ total nitrogen concentrations per treatment after a 5-day period without water renewal were $1.83 \pm 0.10 \mathrm{mg} / \mathrm{L}$ in the controls, $19.26 \pm 1.02 \mathrm{mg} / \mathrm{L}$ in the lowest concentration treatment, $84.82 \pm 3.22 \mathrm{mg} / \mathrm{L}$ in the intermediate concentration treatment, and $172.42 \pm 1.36 \mathrm{mg} / \mathrm{L}$ in the highest concentration treatment. In the $\mathrm{S}$. salamandra experiment, these values were $2.22 \pm 1.50 \mathrm{mg} / \mathrm{L}$ in the controls, $18.00 \pm 1.34 \mathrm{mg} / \mathrm{L}$ in the lowest concentration treatment, and $75.84 \pm 2.52 \mathrm{mg} / \mathrm{L}$ in the highest concentration treatment. Maximum deviations with respect to the nominal levels in total nitrogen concentration were $25 \%$ in the R. dalmatina experiment and $29 \%$ in the S. salamandra one. Individual density did not affect the ammonium nitrate concentrations in any experiment $(p>0.05)$.

\section{Discussion}

The present study shows that elevated individual density, even in conditions of unlimited food resources, acts as a stressor, increasing the toxicity of ammonium nitrate to R. dalmatina tadpoles. Furthermore, exposure to the fertilizer alters the natural influence of density on the incidence of cannibalism among S. salamandra larvae.

Several studies have demonstrated the effects of increased individual density on survival and development of amphibian larvae (e.g. Rose, 1960; Gromko et al., 1973; Wilbur, 1977; Dash and Hota, 1980). For example, Martínez et al. (1996) observed that the survival and growth rates of Pelophylax perezi tadpoles, as well as the proportion of individuals reaching metamorphosis, were higher as density decreased. Eitam et al. (2005) reported a $100 \%$ survival to metamorphosis for larval S. salamandra when they developed individually in aquaria, contrasting with the $43 \%$ survival rate when they grew in groups of six individuals per aquarium. These authors also noted that increased larval density delayed metamorphosis and reduced juvenile body size.

The scientific literature provides several hypotheses to explain the negative effects of increased density on amphibian larval development: (i) competition for resources increases as density increases (Wilbur, 1977; Dash and Hota, 1980); (ii) physical encounters among larvae stress individuals (Gromko et al., 1973); and (iii) in anuran species, the competitive interactions among conspecific tadpoles can be mediated in some cases by the unicellular alga Prototheca richardsi, which grows in the intestinal tract of animals (Beebee, 1991). This alga is excreted through feces and ingested by other tadpoles (Bardsley and Beebee, 2001). Smaller tadpoles proportionately accumulate a higher number of algae than larger ones, which initiates a positive feedback process that leads to arrested growth in the smaller animals. Crump (1981) suggested an energy based model that integrates some of the aforementioned hypotheses; larvae growing at high density have few available resources per capita, expend much energy in avoiding encounters with conspecifics, and show increased metabolic demands in order to fight against detrimental microorganisms that are present in the intestinal tract. In the experiments conducted in the present study, the high frequency of water renewal surely limited the proliferation of growth-inhibiting algae, which happens in static-renewal designs (Justo et al., 1985), and the available resources were unlimited because of ad libitum provision of food. However, animals that grew at elevated density could always suffer an increased stress because of numerous larval encounters.

Most studies analyzing the combined effects of density and environmental pollutants on amphibians have been carried out in mesocosm conditions, using the availability of nutrients as a driving factor for this interaction. For example, herbicides like atrazine can reduce the amount of food for tadpoles by eliminating vegetation from the pools, thereby increasing the starvation probabilities of tadpoles raised in high-density pools where the food requirements are higher (Boone and James, 2003). Non-toxic concentrations of insecticides like carbaryl can favor tadpole survival at high densities by promoting algal growth after removal of zooplankton (Boone and Semlitsch, 2001).

We are unaware of the existence of published work analyzing the effect of individual density on amphibian sensitivity to nitrogenous fertilizers. In this case, low fertilizer concentrations could favor algal growth, thereby promoting nutrient availability for anuran tadpoles (Boone et al., 2005, 2007). Indirectly, urodele larvae could also benefit from fertilizer application, as a high concentration of phytoplankton would favor zooplankton growth. Nevertheless, experiments in mesocosms are required to test these hypotheses; in the present study, the fertilizer acted exclusively as a potential stressor.

Reduction of growth rate is a typical direct effect of ammonium nitrate on amphibian larvae (Xu and Oldham, 1997; Ortiz et al., 2004). In the R. dalmatina experiment, we detected such an effect especially at low density, but when tadpoles grew at high density, the impact of the fertilizer on tadpole growth was ameliorated. Previous studies have demonstrated that small larvae are more sensitive to ammonium nitrate than large ones (Watt and Jarvis, 1997; Ortiz-Santaliestra et al., 2006), and hence the effects on tadpole size can also be mediated by mortality, which could end in the selection of large individuals.

Cannibalism in amphibian larvae is a natural effect that is highly related to elevated densities (e.g. Collins and Cheek, 1983; Nishihara, 1996), especially in urodele species with carnivorous larvae. For example, Semlitsch and Reichling (1989) found that high individual density increased aggressions among Ambystoma talpoideum larvae, which resulted in an inverse relationship between density and larval survival. It could be hypothesized 
that cannibalism would be stimulated by the food shortage occurring when larval density increases. Walls (1998) found increased cannibalism-related mortality in Ambystoma maculatum larvae attributable to food limitation.

With regards to S. salamandra, Csillery and Lengyel (2004) suggested that unlimited food resources significantly ameliorated the effects of density. Accordingly, in the present study, in which no food restriction existed, the occurrence of cannibalism should have been testimonial. However, Degani et al. (1980) observed that addition of food to the water increased differences in size among $S$. salamandra larvae and thus intensified cannibalism. Cannibalism has the advantage of providing a large amount of nutrients with little searching effort. Cannibal larvae grow and metamorphose faster and show a higher survival rate than their non-cannibal conspecifics (Bragg, 1964; Crump, 1990; Wildy et al., 1998; Jordan et al., 2004). These advantages would contribute to the explanation of why, even when food is unlimited, increased larval density contributes to augmenting the frequency of cannibalistic interactions.

Our results demonstrate, for the first time in amphibians, that environmental pollution in general, and ammonium nitrate in particular, may inhibit the habitual, density-dependent cannibalistic behavior in salamander larvae. In addition to the aforementioned advantages, cannibalism contributes to reduced individual density through the removal of cannibalized individuals, another positive effect that disappears as a consequence of ammonium nitrate exposure. As no previous ecotoxicological study has analyzed this response, there is little information to explore the potential reasons behind the observed effect. Ammonium nitrate at moderate levels may negatively affect activity (Xu and Oldham, 1997; Burgett et al., 2007) and escape behaviors in amphibians (Ortiz-Santaliestra et al., 2010b) which could be determinant for the stimulation and/or avoidance of cannibalistic behavior.

\section{Conclusions}

The present paper provides novel information on the ecological effects of environmental pollution in amphibians by testing, for the first time, the effects of nitrogenous fertilizers at different larval densities, and by introducing the cannibalistic interactions as a response in ecotoxicological studies with amphibians. Further experiments should follow to elucidate the mechanisms underlying the reported alteration of cannibalistic behaviors after the exposure of S. salamandra to the fertilizer. Such experiments should include, among others, evaluations of both feeding behavior, response to prodding to assess potential effects on nervous and muscular systems, and energetic status of cannibal and noncannibal individuals as a function of ammonium nitrate exposure and density conditions. Our results highlight the importance of considering natural factors involved in changes in larval densities, such as pond desiccation - with the consequent potential increase in concentration of chemicals dissolved in the water or changes in prey-predator relationships, when estimating the impact of nitrogenous compounds on amphibians in the aquatic environment.

\section{Acknowledgments}

The Navarra and Castilla y León regional governments provided permits for collecting animals. Vanessa Sarasola and Alberto Gosá helped during animal collection. Two anonymous referees provided helpful comments on the manuscript. MEOS is supported by the Juan de la Cierva Program of the Spanish Ministerio de Ciencia e Innovación.

\section{References}

Alarcos, G., Ortiz, M.E., Lizana, M., Aragón, A., Fernández Benéitez, M.J., 2003. La colonización de medios acuáticos por anfibios como herramienta para su conservación: el ejemplo de Arribes del Duero. Munibe Suplemento 16, 114-127.

Altenburger, R., Nendza, M., Schuurmann, G., 2003. Mixture toxicity and its modeling by quantitative structure-activity relationships. Environ. Toxicol. Chem. 22, 1900-1915.

Altwegg, R., 2003. Multistage density dependence in amphibian. Oecologia 136, 46-50.

Bardsley, L., Beebee, T.J.C., 2001. Non-behavioural interference competition between anuran larvae under semi-natural conditions. Oecologia 128, 360-367.

Beebee, T.J.C., 1991. Purification of an agent causing growth inhibition in anuran larvae and its identification as a unicellular unpigmented alga. Can. J. Zool. 69, 2146-2153.

Boone, M.D., 2005. Juvenile frogs compensate for small metamorph size with terrestrial growth: overcoming the effects of larval density and insecticide exposure. J. Herpetol. 39, 416-423.

Boone, M.D., Bridges, C.M., Fairchild, J.F., Little, E.E., 2005. Multiple sublethal chemicals negatively affect tadpoles of the green frog, Rana clamitans. Environ. Toxicol. Chem. 24, 1267-1272.

Boone, M.D., James, S.M., 2003. Interactions of an insecticide, herbicide, and natural stressors in amphibian community mesocosms. Ecol. Appl. 13, 829-841.

Boone, M.D., Semlitsch, R.D., 2001. Interactions of an insecticide with larval density and predation in experimental amphibian communities. Conserv. Biol. 15, 228-238.

Boone, M.D., Semlitsch, R.D., Little, E.E., Doyle, M.C., 2007. Multiple stressors in amphibian communities: effects of chemical contamination, bullfrogs and fish. Ecol. Appl. 17, 291-301.

Bragg, A.N., 1964. Further study of predation and cannibalism in tadpoles of Scaphiopus bombifrons. Herpetologica 20, 17-24.

Buckley, D., Alcobendas, M., García-París, M., Wake, M.H., 2007. Heterochrony, cannibalism, and the evolution of viviparity in Salamandra salamandra. Evol. Dev. 9, 105-115.

Burgett, A.A., Wright, C.D., Smith, G.R., Fortune, D.T., Johnson, S.L., 2007. Impact of ammonium nitrate on wood frog (Rana sylvatica) tadpoles: effects on survivorship and behavior. Herpetol. Conserv. Biol. 2, 29-34.

Chen, Y.H., Su, Y.J., Lin, Y.S., Kam, Y.C., 2001. Inter- and intraclutch competition among oophagous tadpoles of the Taiwanese tree frog, Chirixalus eiffingeri (Anura: Rhacophoridae). Herpetologica 57, 438-448.

Chivers, D.P., Wildy, E.L., Blaustein, A.R., 1997. Eastern long-toed salamander (Ambystoma macrodactylum columbianum) larvae recognize cannibalistic conspecifics. Ethology 103, 187-197.

Collins, J.P., Cheek, J.E., 1983. Effect of food and density on development of typical and cannibalistic salamander larvae in Ambystomatigrinum nebulosum. Am. Zool. 23, 77-84.

Crump, M.L., 1981. Energy accumulation and amphibian metamorphosis. Oecologia 49, $167-169$.

Crump, M.L., 1983. Opportunistic cannibalism by amphibian larvae in temporary aquatic environments. Amer. Nat. 121, 281-289.

Crump, M.L., 1990. Possible enhancement of growth in tadpoles through cannibalism. Copeia 1990, 560-564.

Csillery, K., Lengyel, S., 2004. Density dependence in stream-dwelling larvae of fire salamander (Salamandra salamandra): a field experiment. Amphib. Reptil. 25, 343-349.

Dash, M.C., Hota, A.K., 1980. Density effects on the survival, growth-rate, and metamorphosis of Rana tigrina tadpoles. Ecology 61, 1025-1028.

DeWitt, T.J., Sih, A., Wilson, D.S., 1998. Costs and limits of phenotypic plasticity. Trends Ecol. Evol. 13, 77-81.

Degani, G., Goldenberg, S., Warburg, M.R., 1980. Cannibalistic phenomena in Salamandra salamandra larvae in certain water bodies and under experimental conditions. Hydrobiologia 75, 123-128.

Distel, C.A., Boone, M.D., 2009. Effects of aquatic exposure to the insecticide carbaryl and density on aquatic and terrestrial growth and survival in American toads. Environ. Toxicol. Chem. 28, 1963-1969.

Eitam, A., Blaustein, L., Mangel, M., 2005. Density and intercohort priority effects on larval Salamandra salamandra in temporary pools. Oecologia 146, 36-42.

European Council, 1998. Council Directive 98/83/EC of 3 November 1998 on the Quality of Water Intended for Human Consumption, Official Journal of the European Communities 05/12/98. Publications Office of the European Union, Luxembourg, pp. L330/332-L330/354.

Fairchild, J.F., Lapoint, T.W., Zajicek, J.L., Nelson, M.K., Dwyer, F.J., Lovely, P.A., 1992. Population-level, community-level and ecosystem-level responses of aquatic mesocosms to pulsed doses of a pyrethroid insecticide. Environ. Toxicol. Chem. $11,115-129$.

Fernández-Aláez, M., Fernández-Aláez, C., 2010. Effects of the intense summer desiccation and the autumn filling on the water chemistry in some Mediterranean Ponds. Limnetica 29, 59-74.

Ficetola, G.F., Valota, M., de Bernardi, F., 2006. Temporal variability of spawning site selection in the frog Rana dalmatina: consequences for habitat management. Anim. Biodiv. Conserv. 29, 157-163.

Gosá, A., 1994. Biología reproductiva de la rana ágil, Rana dalmatina (Ranidae, Anura), en Navarra. Munibe 46, 109-189.

Gosner, K.L., 1960. A simplified table for staging anuran embryos and larvae with notes on identification. Herpetologica 16, 183-190. 
Griffis-Kyle, K.L., Ritchie, M.E., 2007. Amphibian survival, growth and development in response to mineral nitrogen exposure and predator cues in the field: an experimental approach. Oecologia 152, 633-642.

Gromko, Mason, M.H., SmithgilSj, F.S., 1973. Analysis of the crowding effect in Rana pipiens tadpoles. J. Exp. Zool. 186, 63-71.

Hanazato, T., Yasuno, M., 1990. Influence of time of application of an insecticide on recovery patterns of a zooplankton community in experimental ponds. Arch. Environ. Contam. Toxicol. 19, 77-83.

Jordan, D.J., Rombough, C.J., Pearl, C.A., McCreary, B., 2004. Cannibalism and predation by western toad (Bufo boreas boreas) larvae in Oregon, USA. West. North Am. Nat. 64, 403-405.

Justo, C.L., Penteado, L.A., Arruda-Soares, H., Mandelli, J., Campos, B., 1985. Ganho de peso do girinos de Rana catesbeiana Shaw, 1802, em criaçăo intensiva, sob diferentes densidades populacionais. Bol. Inst. Pesca 12, 31-37.

Loman, J., 2004. Density regulation in tadpoles of Rana temporaria: a full pond experiment. Ecology 85, 1611-1618.

Martínez, I.P., Alvarez, R., Herráez, M.P., 1996. Growth and metamorphosis of Rana perezi larvae in culture: effects of larval density. Aquaculture 142, 163-170.

Nishihara, A., 1996. Effects of density on growth of head size in larvae of the salamander Hynobius retardatus. Copeia, 478-483.

Ortiz-Santaliestra, M.E., Fernández-Benéitez, M.J., Lizana, M., Marco, A., 2010a. Adaptation to osmotic stress provides protection against ammonium nitrate in Pelophylax perezi embryos. Environ. Pollut. 158, 934-940.

Ortiz-Santaliestra, M.E., Fernández-Benéitez, M.J., Lizana, M., Marco, A. 2011. Responses of toad tadpoles to ammonium nitrate fertilizer and predatory stress: differences between populations on a local scale. Environ. Toxicol. Chem. 30, 1440-1446.

Ortiz-Santaliestra, M.E., Fernández-Benéitez, M.J., Marco, A., Lizana, M., 2010b. Influence of ammonium nitrate on larval anti-predatory responses of two amphibian species. Aquat. Toxicol. 99, 198-204.

Ortiz-Santaliestra, M.E., Marco, A., Fernández, M.J, Lizana, M., 2006. Influence of developmental stage on sensitivity to ammonium nitrate of aquatic stages of amphibians. Environ. Toxicol. Chem. 25, 105-111.

Ortiz, M.E., Marco, A., Saiz, N., Lizana, M., 2004. Impact of ammonium nitrate on growth and survival of six European amphibians. Arch. Environ. Contam. Toxicol. 47, 234-239.

Polis, G.A., 1981. The evolution and dynamics of intraspecific predation. Annu. Rev. Ecol. Syst. 12, 225-251.

Relyea, R.A., 2005. The impact of insecticides and herbicides on the biodiversity and productivity of aquatic communities. Ecol. Appl. 15, 618-627.

Relyea, R.A., Diecks, N., 2008. An unforeseen chain of events: lethal effects of pesticides on frogs at sublethal concentrations. Ecol. Appl. 18, 1728-1742.

Relyea, R., Hoverman, H., 2006. Assessing the ecology in ecotoxicology: a review and synthesis in freshwater systems. Ecol. Lett. 9, 1157-1171.
Richter, J., Martin, L., Beachy, C.K., 2009. Increased larval density induces accelerated metamorphosis independently of growth rate in the frog Rana sphenocephala. J. Herpetol. 43, 551-554.

Rose, S.M., 1960. A feedback mechanism of growth-control in tadpoles. Ecology 41, 188-199.

Sarasola, V., 2010. Ecología y Conservación de Rana dalmatina en la Península Ibérica. Ph.D. Dissertation, Universidad de Salamanca, Salamanca, Spain.

Scott, D.E., 1990. Effects of larval density in Ambystoma opacum - an experiment in large-scale field enclosures. Ecology 71, 296-306.

Scott, D.E., Fore, M.R., 1995. The effect of food limitation on lipid levels, growth, and reproduction in the marbled salamander, Ambystoma opacum. Herpetologica 51, $462-471$.

Semlitsch, R.D., Caldwell, J.P., 1982. Effects of density on growth, metamorphosis, and survivorship in tadpoles of Scaphiopus holbrooki. Ecology 63, 905-911.

Semlitsch, R.D., Reichling, S.B., 1989. Density-dependent injury in larval salamanders. Oecologia 81, 100-103.

Semlitsch, R.D., Walls, S.C., 1993. Competition in two species of larval salamanders - a test of geographic-variation in competitive ability. Copeia 1993, $587-595$.

Sibly, R.M., 1999. Efficient experimental designs for studying stress and population density in animal populations. Ecol. Appl. 9, 496-503.

Skelly, D.K., 1995. Competition and the distribution of spring peeper larvae. Oecologia 103, 203-207.

Van Buskirk, J., Smith, D.C., 1991. Density-dependent population regulation in a salamander. Ecology 72, 1747-1756.

Vitousek, P.M., Aber, J., Howarth, R.W., Likens, G.E., Matson, P.A., Schindler, D.W., Schlesinger, W.H., Tilman, D., 1997. Human alteration of the global nitrogen cycle: causes and consequences. Issues Ecol. 1, 1-16.

Walls, S.C., 1998. Density dependence in a larval salamander: the effects of interference and food limitation. Copeia 1998, 926-935.

Watt, P.J., Jarvis, P., 1997. Survival analysis in palmate newts exposed to ammonium nitrate agricultural fertilizer. Ecotoxicology6, 355-362.

Wilbur, H.M., 1977. Density-dependent aspects of growth and metamorphosis in Bufo americanus. Ecology 58, 196-200.

Wilbur, H.M., 1980. Complex life-cycles. Annu. Rev. Ecol. Syst. 11, 67-93.

Wildy, E.L., Chivers, D.P., Blaustein, A.R., 1999. Shifts in life-history traits as a response to cannibalism in larval long-toed salamanders (Ambystoma macrodactylum). J. Chem. Ecol. 25, 2337-2346.

Wildy, E.L., Chivers, D.P., Kiesecker, J.M., Blaustein, A.R., 1998. Cannibalism enhances growth in larval long-toed salamanders, (Ambystoma macrodactylum). J. Herpetol. 32, 286-289.

Xu, Q., Oldham, R.S., 1997. Lethal and sublethal effects of nitrogen fertilizer ammonium nitrate on common toad (Bufo bufo) tadpoles. Arch. Environ. Contam. Toxicol. 32, 298-303. 